\title{
Circulating blood miRNAs for prostate cancer risk stratification: miRroring the underlying tumor biology with liquid biopsies
}

This article was published in the following Dove Medical Press journal: Research and Reports in Urology

\section{Christianne Hoey ${ }^{1,2}$ \\ Stanley K Liu ${ }^{1-3}$}

'Biological Sciences, Sunnybrook Research Institute, Sunnybrook Health Sciences Centre, Toronto, ON M4N 3M5, Canada; ${ }^{2}$ Department of Medical Biophysics, University of Toronto, Toronto, ON M5G IL7, Canada; ${ }^{3}$ Department of Radiation Oncology, University of Toronto, Toronto, ON M5S 3E2, Canada
Correspondence: Stanley K Liu Biological Sciences, Sunnybrook Research Institute, Sunnybrook Health Sciences Centre, 2075 Bayview Avenue, Rm T2-I42, Toronto, ON M4N 3M5, Canada Tel +l 4164804998

Fax +I 4164806002

Email stanley.liu@sunnybrook.ca

\begin{abstract}
Current risk stratification methods for prostate cancer - although they have seen marked improvements over the past decades - are far from perfect. Despite the significant utility of prostate-specific antigen as a biomarker to monitor for disease recurrence, it cannot predict which tumors will recur or recommend the best treatment for patients. Similarly, although biopsies are imperative for diagnosis and staging, they are saddled with limitations and risks. We must move toward a noninvasive biomarker that has predictive and prognostic efficacy. We therefore review the current literature on circulating miRNA biomarkers, apply their use to two significant clinical problems (ie, how limitations of prostate biopsies can impact diagnosis and treatment management, and the need to tailor treatment for a clinically heterogeneous disease), and evaluate how circulating miRNAs have inherent properties that make them ideal liquid biomarkers. We also outline current gaps in knowledge that must be addressed before they can be implemented into routine clinical practice. With further research on their function and validation of their biomarker utility in large prospective cohorts, circulating miRNAs will likely prove to be the liquid biopsies of tomorrow.
\end{abstract}

Keywords: miRNA, biomarker, prostate cancer, risk stratification, serum, plasma

\section{Prostate cancer in the present day}

Prostate cancer is the most commonly diagnosed non-skin cancer affecting men, and the second most common cancer worldwide, with over 1 million cases diagnosed and 300,000 deaths per year according to GLOBOCAN 2012. ${ }^{1}$ Despite developments in prostate cancer diagnosis, largely due to the discovery of prostate-specific antigen (PSA) and advancements in imaging technology, a considerable number of men will relapse and succumb to this disease. Improved initial risk stratification would guide better treatment management and patient outcomes.

\section{Current methods of prostate cancer risk stratification}

The current risk stratification for prostate cancer utilizes tumor extent, Gleason grading, and PSA..$^{2,3}$ Gleason grade has the greatest prognostic significance, ${ }^{3,4}$ and is based on the histopathological analysis of needle core biopsy tissue. ${ }^{4}$ Despite the universal reliance on biopsies for prostate cancer risk stratification and treatment management, there remain many limitations. From a patient perspective, biopsies are invasive, uncomfortable, and can lead to side effects such as hematuria, rectal bleeding, pain, and infection. ${ }^{5}$ Since prostate biopsy samples are typically taken through a transrectal approach, there is a high risk of infection, and to minimize this risk, prophylactic 
antibiotics are administered to patients before biopsy procedures. ${ }^{5}$ However, the development of antibiotic-resistant organisms has resulted in an increased incidence of potentially life threatening sepsis. ${ }^{6}$ From a treatment perspective, although grading of prostate biopsies has remained the gold standard for diagnosis, it is accepted that needle biopsies may not be fully representative of the entire tumor, resulting in discordance in the Gleason grade between the diagnostic biopsy and the radical prostatectomy specimen. ${ }^{7}$ Additionally, intratumor genetic heterogeneity is increasingly being recognized as a confounding factor in diagnosis. Together, the limitations inherent to biopsies can influence upfront management decisions. As such, there is a need to identify less invasive biomarkers, such as circulating liquid (eg, serum, plasma) biomarkers that may reduce or even eliminate the need for biopsy procedures. We discuss this in more detail in the section "Clinical problem 1."

\section{Prostate cancer imaging}

The development of advanced imaging technologies, such as magnetic resonance imaging (MRI), is helping to address some of these limitations. Prostate Imaging Reporting and Data System (PI-RADS) is a multi-parametric MRI (mpMRI) scoring system that classifies prostate tumors into categories based on their likelihood of clinically significant cancer being present or not. A prospective study by Pokorny et al showed that MRI-guided biopsy (MGB) was less likely to detect clinically insignificant low-grade prostate cancers $(89.4 \%$ reduction in detection) and more likely to detect clinically significant intermediate- or high-grade disease (17.7\% increase in detection) compared to transrectal ultrasonography-guided biopsy (TRUS-biopsy), and ultimately reduced the need for biopsies by $51 \%{ }^{8}$ Two recent landmark randomized control trials, PROMIS and PRECISION, evaluated mpMRI vs TRUS-biopsy for prostate cancer diagnosis. In the PROMIS trial, mpMRI was more sensitive (93\%; 95\% CI: 88\%-96\%) than TRUS-biopsy (48\%; 95\% CI: 42\%-55\%) to identify clinically significant disease, although at the cost of reduced specificity. ${ }^{9}$ Additionally, mpMRI could potentially allow $27 \%$ of patients to avoid an upfront biopsy. Similarly, the PRECISION trial demonstrated superiority of MGB over standard TRUS-biopsy for detection of clinically significant cancer, where clinically significant cancer was found in $38 \%$ of men with MGB compared to $26 \%$ of men using TRUS-biopsy (95\% CI: 4\%-20\%; P=0.005). ${ }^{10}$ Only $12 \%$ of men with PI-RADS 3 lesions were found to have clinically significant cancer on targeted biopsy compared to $60 \%$ and $83 \%$, respectively, for PI-RADS 4 and 5, highlighting the considerable amount of ambiguity when tumors are scored with PI-RADS $3 .^{10}$ The limitations of MRI were further revealed in a recent study by Johnson et al, which found that mpMRI had a low sensitivity for detecting prostate cancer foci: mpMRI detected $45 \%$ of all lesions $(95 \% \mathrm{CI}$ : $42 \%-47 \%)$, and $65 \%$ of clinically significant lesions $(95 \%$ CI: $61 \%-69 \%) .{ }^{11}$ Therefore, even in the era of mpMRI, there is a vital need to improve the diagnostic accuracy of detecting clinically significant prostate cancer, particularly in the case of patients with PI-RADS 3 cancer.

\section{Tissue-based genomic tests for prostate cancer risk stratification}

In an attempt to improve the detection of clinically aggressive prostate cancer, there has been intensive research and development to create genomic tests that capture the biological phenotype of a patient's prostate cancer. Several of these tests are tissue based, including Decipher and Prolaris, which require biopsy or radical prostatectomy samples. GenomeDx's Decipher is a tool for patients who have undergone radical prostatectomy to determine the probability of metastasis and tumor aggressiveness. ${ }^{12,13}$ Decipher evaluates the expression of 22 RNA biomarkers in the tumor to calculate the probability of metastasis within 5 years of surgery. Prolaris, developed by Myriad Genetic Laboratories (Salt Lake City, UT, USA), uses a 46-gene expression signature for risk assessment. ${ }^{14}$ Prolaris uses tumor tissue from needle biopsy or radical prostatectomy samples to calculate the probability of disease progression. Another genomic test was developed by Lalonde et al, which utilizes a 31-locus genomic classifier from tissue specimens to identify patients who are more likely to have biochemical recurrence (BCR) and metastatic spread. ${ }^{15}$ However, these tissue-based tests are invasive and those using biopsies are still subject to the limitations discussed above. Accordingly, noninvasive, liquid-based tests are being developed.

\section{Noninvasive biomarkers}

There is a significant push in the field to identify biomarkers found in biofluids, such as blood. These circulating biomarkers (found in plasma and serum) seem to have limitless potential. Their noninvasive nature increases patient compliance and allows for easy and inexpensive serial sampling. This is particularly intriguing as it would allow for treatment response and disease progression to be monitored over time. ${ }^{16}$ It has also been suggested that liquid biomarkers may be a more representative illustration of the tumor's underlying genomic blueprint compared to tissue-based markers. ${ }^{16}$ Furthermore, liquid biopsies have been described to be diagnostic, predictive, and prognostic. 


\section{Current liquid-based genomic tests for prostate cancer risk stratification}

Prostate cancer antigen 3 (PCA3) is a predictive post-digital rectal exam (DRE) urine-based test used to help determine whether an elevated PSA test is likely caused by prostate cancer. ${ }^{17,18}$ PCA3 testing can help physicians decide whether a biopsy is required. Although this test is very useful in its ability to help distinguish patients who should be selected for biopsy compared to those who can be spared this invasive procedure, it cannot predict disease aggressiveness or prognosis. The commercially available 4Kscore Test (OPKO Health Inc, Miami, FL, USA) is a prognostic blood test that evaluates a patient's risk of aggressive prostate cancer prior to biopsy, and poor clinical outcomes within 20 years. ${ }^{19-22}$ The 4 Kscore Test uses an algorithm consisting of the levels of four markers in the serum - total PSA, free PSA, intact PSA, and human kallikrein 2 - in addition to the patient's age, DRE status, and history of prior biopsy to determine the probability of identifying clinically significant cancer (Gleason 7 and above) from a biopsy. It can help determine which patients are high risk and would benefit from a biopsy, and those who are low risk and can avoid receiving a biopsy. The 4Kscore Test has been independently validated in large, multi-institutional studies showing its utility in predicting high-grade prostate cancer, and reducing the need for biopsies in low-grade cancer patients. ${ }^{19,23-27}$ However, it does not eliminate the need of biopsies for others; patients at high risk for prostate cancer (determined by either the PCA3 or 4Kscore tests) will still need to have a biopsy. Furthermore, these tests cannot guide treatment planning or identify which patients will have recurrence after treatment. Therefore, there is a need to identify noninvasive biomarkers that can be used for patient risk stratification at initial diagnosis and for serial monitoring of their disease throughout treatment, independent of biopsy or surgical tissue.

\section{Circulating miRNAs are perfect candidates for noninvasive biomarkers}

miRNAs (also represented as miR-) have recently gained interest as promising candidates for noninvasive circulating biomarkers. Circulating miRNAs have been shown to be stable in bodily fluids, expressed at detectable levels, and representative of cancer. ${ }^{28,29}$ miRNAs are also thought to be superior to proteins as biomarkers, as they are more stable in biological fluids and yield more straightforward interpretations (ie, miRNA expression level correlates with activity, miRNAs are not translated from mRNA like proteins, and they do not undergo posttranscriptional or posttranslational modifications). ${ }^{30}$
miRNAs are small ( $\sim 20-25$ nucleotides in length), noncoding RNAs that downregulate expression of target genes. ${ }^{31}$ It is estimated that there are over 1,000 miRNAs encoded in the human genome, which regulate $~ 50 \%$ of all protein coding genes..$^{32-34}$ miRNAs regulate genes involved in all cellular processes, which highlights their widespread importance in gene regulation. miRNAs decrease gene expression by binding to the $3^{\prime}$-untranslated region of a target mRNA. This binding results in translation inhibition or transcript degradation. If transcriptional repression occurs, it will do so in one of four ways: 1) inhibition of translation initiation; 2) inhibition of translation elongation; 3) co-translational protein degradation; or 4) premature termination of translation. ${ }^{35}$ Target degradation is recognized to be the major result of miRNA-mRNA binding. ${ }^{35}$

miRNAs are involved in all cell processes and have been an object of much interest due to their aberrant expression and role in cancer. They are particularly intriguing due to the fact that one miRNA can target and downregulate hundreds of gene transcripts. Since individual miRNAs can regulate multiple cellular pathways simultaneously ${ }^{36}$ small perturbations in miRNA expression could lead to harmful downstream effects resulting in cancer development, progression, and recurrence. Many miRNAs have been characterized for their role in prostate cancer. ${ }^{37,38} \mathrm{We}$ have previously described various miRNAs for their role in cell cycle progression, metastatic potential, tumor aggression, and therapy resistance: miR-95, ${ }^{39}$ miR-106a,${ }^{40}$ miR-330-3p,${ }^{41}$ miR-620. ${ }^{42}$

miRNAs have been described to be preferentially enriched in extracellular vesicles (EVs, also known as exosomes). ${ }^{43}$ Exosomes are small vesicles formed from the inward budding of endosomes, which therefore contain cellular components from the cytosol. ${ }^{44}$ Exosomes facilitate cell-cell communication in a paracrine or endocrine manner. ${ }^{43,45}$ It is thought that exosomal contents, such as miRNAs, may be involved in epigenetic reprogramming of the target cell. ${ }^{46}$ Urine exosomes are a particularly rich source of prostate cancer-specific transcripts when collected from post-DRE urine ${ }^{47}$ A clinically validated noninvasive test, ExoDx Prostate IntelliScore (Exosome Diagnostics, Waltham, MA, USA), assesses the expression of three genes from urine specimens to distinguish benign and low-grade prostate cancer from high-grade prostate cancer. ${ }^{48,49}$ This assay can help determine whether patients with elevated PSA require a biopsy. Although ExoDx is a urine-based test and this review is focusing on circulating blood biomarkers, it is worthwhile mentioning since post-DRE urine samples are likely to be highly enriched with prostate cells and EVs. miRNAs are 
likely enriched in EVs, regardless of whether they are collected in urine or other biofluids, such as plasma and serum.

miRNAs are particularly promising biomarker candidates as they have the characteristics of an ideal biomarker. A perfect biomarker must be specific to the tissue of interest and be able to distinguish the particular disease state of interest within that tissue; be sensitive so that the extent of the pathology is mirrored in the expression of the biomarker; have a long half-life; be easy, fast, and inexpensive to detect; and not be invasive for the patient. ${ }^{16,50}$ miRNAs are known to be highly stable in serum and plasma, and are very resistant to boiling, $\mathrm{pH}$ changes, repeated freeze-thaw cycles, and fragmentation by chemical or enzymes. ${ }^{16,50,51}$ It is thought that miRNAs are highly stable in serum and plasma due to their incorporation in EVs or protein complexes. ${ }^{43,52}$ The future of prostate cancer risk stratification will likely entail the identification of unique circulating miRNA signatures that allow for treatment regimens to be tailored to each individual patient. In the following section we will be discussing the potential utility of circulating miRNAs to address two significant clinical problems.

\section{Clinical problem I: limitations of prostate biopsies can impact diagnosis and treatment management}

A significant clinical problem of biopsies is that they are often not representative of the entire tumor, due to random sampling and geographical miss of the tumor during biopsy collection. ${ }^{53}$ The heterogenous nature of cancer indeed further complicates obtaining an accurate overview of tumor burden. Since the cancer may have progressed to higher tumor grades in different areas of the prostate, it is imperative to biopsy representative tumor tissue for accurate tumor staging. As TRUS-biopsies are collected from a posterior approach, it is harder to biopsy anterior lesions, and thus may result in missing clinically significant lesions. ${ }^{54}$ These procedural issues may limit our ability to accurately classify the disease, and thereby impact optimal decision making.

It has been estimated that Gleason grade assigned to needle biopsy is discordant with the whole radical prostatectomy specimen in around $50 \%$ of cases (Humphrey: 43\%; Evans et al: 54.5\%; ${ }^{45}$ Kvåle et al: 53\%, ${ }^{56}$ King: $41 \%{ }^{57}$ ). Epstein et al assessed 7,643 matching biopsies and radical prostatectomy samples and found that there was substantial discordance between the two: ${ }^{58}$ Almost $40 \%$ of biopsy Gleason 5-6 cases were upgraded to higher Gleason grades after radical prostatectomy. Half of Gleason 3+4 cases were either upgraded or downgraded after radical prostatectomy analyses, and the other half showed the same grade. Assuming this study is representative of the population of patients receiving biopsies, this suggests that almost half of the men undergoing active surveillance may need upfront definitive treatment, and approximately one quarter of men with biopsy Gleason 3+4 who received treatment could have been placed on active surveillance and avoided the toxicities of treatment. Since this discordance in grading between biopsy and radical prostatectomy samples follows no pattern (ie, sometimes upgraded and other times downgraded), we cannot assume that treatment should be more aggressive as this would lead to overtreatment and side effects for some of these men. Furthermore, studies have demonstrated that there can be considerable discordance in Gleason grading between different pathologists and institutions. ${ }^{59-62}$ In addition, the reliance on biopsies poses a unique problem for radiation therapy, as tumor tissue is not collected after treatment. Due to the high discrepancy between biopsy and whole tumor pathological grading, there is an even greater chance of undertreatment or overtreatment in this setting. Relying on biopsy specimens for tumor staging poses various questions: does the patient actually have Gleason 6 disease as identified in the biopsy, or do they have Gleason 7, but was the pattern 4 disease missed? The limitations of biopsies can translate to falsely staging a tumor as Gleason score $3+4$, since most of the scores biopsied were pattern 3 , when in reality the majority of the tumor is pattern 4. As previously discussed, mpMRI has helped increase the accuracy of diagnosis with its superior sensitivity ( $>90 \%$ ) compared to biopsy. ${ }^{9,10,63}$ However, the aforementioned issues with PI-RADS scoring means that there is still significant room for improvement. Biomarkers should theoretically originate from any and all areas within the prostate to yield a more accurate representation of the disease. ${ }^{64,65}$

Circulating biomarkers could prove to have clinical utility allowing for superior diagnosis and treatment of prostate cancer. We need to move toward integrating new analyses that improve risk stratification to reduce overtreatment of low-risk disease and undertreatment of high-risk disease.

\section{Clinical problem 2: tailoring treatment for a clinically heterogeneous disease}

Despite these difficulties of accurately staging a tumor, this is just the tip of the iceberg: deciding on a suitable treatment plan is even more challenging. Although cancers are classified into different Gleason grades, the underlying molecular and 
genetic heterogeneity poses a unique problem to every case - each individual tumor may behave differently to the same treatment. It is therefore imperative to discover biologically relevant biomarkers that can predict each cancer's unique disease trajectory after treatment. We need biomarkers that describe how aggressively the cancer will behave so we can tailor treatment to each individual patient. There are two situations for prostate cancer where predictive biomarkers are particularly desirable: active surveillance and Gleason 7/intermediate-risk cohorts.

\section{Active surveillance: to treat or not to treat, that is the question}

Men diagnosed with low-risk (Gleason $\leq 6$, PSA $\leq 10 \mathrm{ng} / \mathrm{mL}$, and $\leq$ stage T2A) localized prostate cancer can be placed on active surveillance. Research has shown that for patients with low-risk disease, treatment offers minimal benefits for disease control compared to active disease monitoring, which can improve quality of life by reducing treatment-related toxicities. ${ }^{66,67}$ In active surveillance, disease progression is monitored carefully and frequently based on PSA kinetics and/or histological progression. ${ }^{6}$ If cancer does progress to more advanced stages (most commonly determined by short PSA doubling time or grade progression), patients will be treated with radical prostatectomy or radiotherapy, with or without androgen deprivation therapy (ADT).$^{68}$ Active surveillance provides a safe and effective option for such patients. However, there are some patients on active surveillance who should have received upfront treatment, and others who were not put on active surveillance but could have been.

\section{Tumor heterogeneity of intermediate-risk disease: spotting a wolf in sheep's clothing}

It is well understood that no two tumors will behave the same way, including their response to treatment. This issue is even more obvious in intermediate-risk prostate cancers. The National Comprehensive Cancer Network describes intermediate-risk prostate cancer as having one of the following high-risk features: clinical tumor stage T2b or T2c; Gleason score 7; or initial PSA $10-20 \mu \mathrm{g} / \mathrm{L}{ }^{69}$

There is considerable heterogeneity in outcomes among patients with intermediate-risk disease. A retrospective study by Stark et al looked at biopsy and radical prostatectomy specimens to infer prostate cancer-specific mortality between patients with Gleason $3+4$ and Gleason $4+3$ disease. They found that men with Gleason $4+3$ cancer had on average three-fold higher mortality rates compared to men with Gleason $3+4$ disease. ${ }^{70}$ A study by Viers et al showed that Gleason 4 pattern in the positive surgical margin was associated with significantly worse 15-year BCR-free, cancer-specific, and systemic progression-free survival. ${ }^{71}$ Similarly, a retrospective study by Wright et al found that in men undergoing surgery or radiotherapy, Gleason $4+3$ patients showed increased rates of recurrence, disease progression, and prostate cancer-specific mortality compared to Gleason $3+4$ patients. ${ }^{72}$ Furthermore, no differences in prostate cancer-specific mortality were seen between Gleason $4+3$ and Gleason $8-10$, suggesting that Gleason $4+3$ should be treated as high-risk disease. ${ }^{72}$ Since Gleason 7 cancers have been found to behave heterogeneously and show a very fine histological line between $3+4$ and $4+3$ cancers, ${ }^{73}$ a new grading system is being implemented to separate Gleason $3+4$ and Gleason 4+3 disease. The new Epstein Grade Group classification was found to improve accuracy of cancer stratification. ${ }^{73-75}$

Due to the significant heterogeneity in intermediate-risk disease, whether Gleason 3+4 disease should be placed on active surveillance instead of definitive treatment has even been questioned. However, in a recent study at Sunnybrook Health Sciences Centre, Musunuru et al reported on the 15 -year metastasis-free survival of low- and intermediate-risk prostate cancer patients on active surveillance: Gleason 6 or less $(\mathrm{PSA} \leq 10 \mathrm{ng} / \mathrm{mL})=94.1 \%$; Gleason 6 or less (PSA 10-20 $\mathrm{ng} / \mathrm{mL})=94.1 \%$; Gleason $3+4($ PSA $\leq 20 \mathrm{ng} / \mathrm{mL})=83.6 \%$; and Gleason $4+3(\mathrm{PSA} \leq 20 \mathrm{ng} / \mathrm{mL})=63.2 \%{ }^{76}$ Despite the pronounced improved survival of patients with Gleason $3+4$ compared to Gleason $4+3$ disease, the authors do not recommend active surveillance for any Gleason 7 prostate cancer. Although it is clear that Gleason $4+3$ patients should not be placed on active surveillance, there remains a controversy as to whether select Gleason $3+4$ patients could be placed on active surveillance or should receive upfront definitive treatment. ${ }^{68,76,77}$ Perhaps, with the use of circulating miRNA biomarkers, we will be able to precisely distinguish a subset of Gleason $3+4$ patients that can be safely placed on active surveillance and avoid side effects of treatment.

Once a decision is made to treat intermediate-risk disease, we are led to another very pressing clinical question of how aggressively we should treat the cancer? Is dose-escalated radiotherapy (ie, higher doses of external beam therapy, or brachytherapy) required here? Should systemic therapies (ie, ADT, abiraterone, or enzalutamide) be added to the treatment cocktail? The underlying question is how can aggressive intermediate-risk prostate cancer be distinguished from those that will behave indolently throughout the course of their disease trajectory? We believe that the answer lies with 
circulating miRNA biomarkers, which perhaps can yield a more holistic view of heterogeneity within the tumor.

\section{Utilizing circulating miRNA biomarkers to address clinical problems \\ Clinical problem I: limitations of prostate biopsies can impact diagnosis and treatment management}

As treatment management depends on an accurate diagnosis, this could not be more imperative for improved patient outcomes. Circulating biomarkers may overcome the limitations of biopsies and imaging. miRNA secreted from prostate cancer cells into the blood are thought to be representative of the overall disease, and can noninvasively identify the presence of clinically significant cancer, independent of the current imaging and pathological biomarkers.

Many miRNAs have been described as diagnostic biomarkers due to their upregulation in prostate cancer compared to normal tissue: let-7a, miR-16, miR-26a, miR-24b, miR92a/b, miR-103, miR-107, miR-141, miR-197, miR-328, miR-485-3p, miR-574-3p, miR-636, miR-640, miR-766, miR-855-5p; and due to their downregulation in prostate cancer compared to normal tissue: $\mathrm{miR}-200 \mathrm{c}$, miR-223; and the list goes on.$^{52,78-83}$ For the purposes of this paper, however, we will focus on those that have been described as prostate cancer predictive or prognostic biomarkers (Table 1).

A study recently published by Liu et al identified a serum 3-miRNA signature (miR-24, miR-223, and miR-375), which was able to better distinguish indolent vs aggressive prostate cancer in patients on active surveillance (area under the curve $[\mathrm{AUC}]=0.690 ; 95 \% \mathrm{CI}=0.596-0.784$ ) compared to PSA $(\mathrm{AUC}=0.667 ; 95 \% \mathrm{CI}=0.580-0.754) .{ }^{84}$ The 3 -miRNA signature in combination with PSA improved the accuracy of detecting aggressive disease (AUC $=0.700 ; 95 \% \mathrm{CI}$ $=0.682-0.884) \cdot{ }^{84}$ Alhasan et al discovered a 5-miRNA serum signature (miR-106a, miR-135a*, miR-200c, miR-433, and miR-605) to predict very high-risk aggressive prostate cancer. ${ }^{80}$ Moltzahn et al identified a diagnostic and prognostic serum miRNA signature: low expression of miR-24 and miR-223 was found in prostate cancer patients compared to healthy controls, whereas miR-93, miR-106a, and miR451 showed high expression in cancer patients compared to controls. ${ }^{79}$ Furthermore, miR-93, miR-106a, and miR-24 were able to distinguish low- and intermediate-risk prostate cancer patients; miR-24, miR-93, miR-106a, miR-223, and miR-451 were able to distinguish low- and high-risk patients.
Similarly, a study by Sharova et al also identified miR-106a and miR-223 as promising liquid biomarkers in prostate cancer. Using plasma samples from patients with elevated PSA, $\mathrm{miR}-106 \mathrm{a} / \mathrm{miR}-130 \mathrm{~b}$ and $\mathrm{miR}-106 \mathrm{a} / \mathrm{miR}-223$ ratios were able to distinguish between patients whose biopsy yielded localized prostate cancer and benign prostatic hyperplasia (BPH) ${ }^{85}$ Shen et al discovered that four plasma miRNAs were able to predict prostate cancer aggressiveness. High expression of miR-20a and miR-21 was found in high-risk Cancer of the Prostate Risk Assessment (CAPRA) score patients; high miR-21 and miR-145 were seen in intermediate- and high-D'Amico score compared to low-score patients; and miR-21 and miR-221 were able to differentiate intermediate- and low-risk CAPRA score patients. ${ }^{86}$ When combined into a signature, miR-20a, miR-21, and miR-145 were able to distinguish patients with intermediate- vs low-risk D'Amico scores $(\mathrm{AUC}=0.763$, sensitivity $=44.4 \%$, specificity $=86.8 \%$; $P=0.044) .{ }^{86}$ The authors further described a signature with all four miRNAs, where miR-20a, miR-21, miR-145, and miR221 could distinguish high- and low-risk D'Amico scores (AUC $=0.0824$, sensitivity $=29.4 \%$, specificity $=97.4 \%$; $P=0.02$ ). Various other predictive miRNA biomarkers have been identified, and their expression profiles can be used to distinguish low-, intermediate-, and high-risk prostate cancer and/or disease progression: miR-9*, miR-15b, miR-16-106b, miR-141, miR-148a, miR-195, miR-378*, miR-516a-3p, and miR-1290. ${ }^{86-92}$ These results are summarized in Table 1.

\section{Clinical problem 2: tailoring treatment for a clinically heterogeneous disease}

Circulating biomarkers may overcome the current limitations of prostate cancer risk stratification by providing a more representative and holistic indication of tumor stage and progression, and guide treatment decisions.

Biomarkers that would prove useful to address this clinical problem are predictive and prognostic. A predictive biomarker provides information about how a patient's cancer will respond to a particular treatment. ${ }^{93}$ It can be used to predict which therapy a patient will respond best to, and monitor their response during the therapeutic intervention. A prognostic biomarker is one that can independently provide information about the outcome of a patient's disease, such as risk of relapse and disease-specific mortality. ${ }^{93}$

Identifying which treatment(s) will be most effective for each patient is imperative for optimal patient outcomes; however, we currently do not have a tool that can be used for this. Circulating miRNAs are an ideal candidate for this; however, 
Table I Circulating blood miRNAs identified for biomarker utility in preclinical studies

\begin{tabular}{|c|c|c|c|c|c|c|}
\hline \multirow[t]{2}{*}{ miRNA } & \multirow[t]{2}{*}{ Fluid } & \multirow[t]{2}{*}{ Biomarker } & \multirow[t]{2}{*}{ Results } & \multicolumn{2}{|c|}{ Cohort size } & \multirow[t]{2}{*}{ Reference } \\
\hline & & & & Cases & Controls & \\
\hline let-7a & $\begin{array}{l}\text { Whole } \\
\text { blood }\end{array}$ & $\begin{array}{l}\text { Diagnostic, } \\
\text { prognostic }\end{array}$ & $\begin{array}{l}\text { Decrease in PCa vs BPH; decreased expression with increasing } \\
\text { D'Amico risk stratification }\end{array}$ & 75 & 27 & 83 \\
\hline miR-9* & Serum & Prognostic & Increase in patients with metastatic PCa & 113 & - & 87 \\
\hline miR-I5b & Plasma & Prognostic & Increased expression associated with high PSA after RP & 79 & 33 & 92 \\
\hline miR-16 & Plasma & Diagnostic & $\begin{array}{l}\text { Increased expression associated with high-grade (Gleason 8-10) } \\
\text { disease }\end{array}$ & 79 & 33 & 92 \\
\hline \multirow[t]{2}{*}{ miR-20a } & Plasma & Prognostic & $\begin{array}{l}\text { Increase in high-risk CAPRA score patients. Signature of miR-20a, } \\
\text { miR-2I, and miR-I } 45 \text { could distinguish patients with intermediate- } \\
\text { vs low-risk D'Amico scores. Signature of miR-20a, miR-2I, miR- } \\
\text { I45, and miR-22 I could distinguish patients with high- vs low-risk } \\
\text { D'Amico scores }\end{array}$ & 82 & - & 86 \\
\hline & $\begin{array}{l}\text { Serum, } \\
\text { plasma }\end{array}$ & $\begin{array}{l}\text { Predictive, } \\
\text { prognostic }\end{array}$ & $\begin{array}{l}\text { Low expression pre-docetaxel chemotherapy associated with PSA } \\
\text { response in CRPC patients }\end{array}$ & 97 & - & 94 \\
\hline \multirow[t]{2}{*}{ miR-2I } & Plasma & Prognostic & $\begin{array}{l}\text { Increase in patients with high-risk CAPRA scores. Increase in } \\
\text { patients with intermediate- and high-risk vs low-risk D'Amico } \\
\text { scores. Differentiate patients with intermediate- vs low-risk } \\
\text { CAPRA scores. Signature of miR-20a, miR-2I, and miR-I45 } \\
\text { could distinguish patients with intermediate- vs low-risk D'Amico } \\
\text { scores. Signature of miR-20a, miR-2I, miR-145, and miR-22I could } \\
\text { distinguish patients with high- vs low-risk D'Amico scores }\end{array}$ & 82 & - & 86 \\
\hline & Serum & Predictive & $\begin{array}{l}\text { Increase in mCRPC. High expression associated with docetaxel } \\
\text { resistance }\end{array}$ & 50 & 6 & 95 \\
\hline miR-24 & Serum & Prognostic & Decrease in PCa: healthy $>$ low risk $>$ intermediate $>$ high risk & 36 & 12 & 79 \\
\hline miR-93 & Serum & $\begin{array}{l}\text { Diagnostic, } \\
\text { prognostic }\end{array}$ & $\begin{array}{l}\text { Increase in cancer vs healthy. Higher in high risk vs low and } \\
\text { intermediate risk }\end{array}$ & 36 & 12 & 79 \\
\hline \multirow[t]{3}{*}{ miR-106a } & Serum & Prognostic & Increase in aggressive $\mathrm{PCa}$ & 12 & 4 & 80 \\
\hline & Serum & Prognostic & Increase in PCa: high $>$ intermediate $>$ low $>$ healthy & 36 & 12 & 79 \\
\hline & Plasma & Diagnostic & Part of miRNA signature to distinguish $\mathrm{PCa}$ and $\mathrm{BPH}$ & 36 & 31 & 85 \\
\hline miR-106b & Plasma & Prognostic & Increased expression associated with high PSA after RP & 79 & 33 & 92 \\
\hline miR-I30b & Plasma & Diagnostic & Part of miRNA signature to distinguish PCa and BPH & 36 & 31 & 85 \\
\hline miR-I35a* & Serum & Prognostic & Decrease in aggressive $\mathrm{PCa}$ & 12 & 4 & 80 \\
\hline \multirow[t]{5}{*}{ miR-I4I } & $\begin{array}{l}\text { Whole } \\
\text { blood }\end{array}$ & $\begin{array}{l}\text { Diagnostic, } \\
\text { prognostic }\end{array}$ & $\begin{array}{l}\text { Increase in PCa vs BPH. Increased expression with increasing } \\
\text { D'Amico risk stratification. Expression decreased after radical } \\
\text { prostatectomy }\end{array}$ & 75 & 27 & 83 \\
\hline & Serum & Prognostic & $\begin{array}{l}\text { Increase in patients with metastatic PCa. Increase in Gleason } 8 \text { vs } \\
\text { Gleason } 7\end{array}$ & 113 & - & 87 \\
\hline & Serum & Prognostic & $\begin{array}{l}\text { Increase in patients with bone metastasis, and increased } \\
\text { expression correlated with more bone lesions }\end{array}$ & 30 & 26 & 88 \\
\hline & Serum & Prognostic & $\begin{array}{l}\text { Increase in high-risk and CRPC serum samples compared to low- } \\
\text { risk localized PCa. Increase in low-risk localized and metastatic } \\
\text { tumor specimens vs normal prostate tissue }\end{array}$ & 84 & - & 89 \\
\hline & Serum & Prognostic & $\begin{array}{l}\text { Increase in serum EVs of metastatic PCa compared to } \\
\text { nonrecurrent PCa patients }\end{array}$ & 47 & 72 & 90 \\
\hline miR-I45 & Plasma & Prognostic & $\begin{array}{l}\text { Increase in patients with intermediate- and high-risk vs low-risk } \\
\text { D'Amico scores. Signature of miR-20a, miR-2I, and miR-I45 } \\
\text { could distinguish patients with intermediate- vs low-risk D'Amico } \\
\text { scores. Signature of miR-20a, miR-2I, miR-I45, and miR-22I could } \\
\text { distinguish patients with high- vs low-risk D'Amico scores }\end{array}$ & 82 & - & 86 \\
\hline miR-I46a & $\begin{array}{l}\text { Serum, } \\
\text { plasma }\end{array}$ & $\begin{array}{l}\text { Predictive, } \\
\text { prognostic }\end{array}$ & $\begin{array}{l}\text { Low expression pre-docetaxel chemotherapy associated with PSA } \\
\text { response in CRPC patients }\end{array}$ & 97 & - & 94 \\
\hline miR-I48a & Plasma & $\begin{array}{l}\text { Diagnostic, } \\
\text { prognostic }\end{array}$ & $\begin{array}{l}\text { Increased expression associated with high PSA after RP and high- } \\
\text { grade (Gleason 8-10) disease }\end{array}$ & 79 & 33 & 92 \\
\hline miR-I95 & Plasma & Diagnostic & $\begin{array}{l}\text { Increased expression associated with high-grade (Gleason 8-10) } \\
\text { disease }\end{array}$ & 79 & 33 & 92 \\
\hline
\end{tabular}


Table I (Continued)

\begin{tabular}{|c|c|c|c|c|c|c|}
\hline \multirow[t]{2}{*}{ miRNA } & \multirow[t]{2}{*}{ Fluid } & \multirow[t]{2}{*}{ Biomarker } & \multirow[t]{2}{*}{ Results } & \multicolumn{2}{|c|}{ Cohort size } & \multirow[t]{2}{*}{ Reference } \\
\hline & & & & Cases & Controls & \\
\hline miR-200a & $\begin{array}{l}\text { Serum, } \\
\text { plasma }\end{array}$ & $\begin{array}{l}\text { Predictive, } \\
\text { prognostic }\end{array}$ & $\begin{array}{l}\text { High expression pre-docetaxel chemotherapy associated with } \\
\text { decreased survival in CRPC patients }\end{array}$ & 97 & - & 94 \\
\hline $\mathrm{miR}-200 \mathrm{~b}$ & $\begin{array}{l}\text { Serum, } \\
\text { plasma }\end{array}$ & $\begin{array}{l}\text { Predictive, } \\
\text { prognostic }\end{array}$ & $\begin{array}{l}\text { High expression pre-docetaxel chemotherapy associated with } \\
\text { decreased survival, PSA response in CRPC patients }\end{array}$ & 97 & - & 94 \\
\hline \multirow[t]{2}{*}{ miR-200c } & Serum & $\begin{array}{l}\text { Diagnostic, } \\
\text { prognostic }\end{array}$ & Decrease in aggressive $\mathrm{PCa}$ & 12 & 4 & 80 \\
\hline & $\begin{array}{l}\text { Serum, } \\
\text { plasma }\end{array}$ & $\begin{array}{l}\text { Predictive, } \\
\text { prognostic }\end{array}$ & $\begin{array}{l}\text { High expression pre-docetaxel chemotherapy associated with } \\
\text { decreased survival, PSA response in CRPC patients }\end{array}$ & 97 & - & 94 \\
\hline miR-22I & Plasma & Prognostic & $\begin{array}{l}\text { Differentiate patients with intermediate- vs low-risk CAPRA } \\
\text { scores. Signature of miR-20a, miR-2I, miR-I45, and miR-22I could } \\
\text { distinguish patients with high- vs low-risk D’Amico scores }\end{array}$ & 82 & - & 86 \\
\hline miR-222 & $\begin{array}{l}\text { Serum, } \\
\text { plasma }\end{array}$ & $\begin{array}{l}\text { Predictive, } \\
\text { prognostic }\end{array}$ & $\begin{array}{l}\text { Low expression pre-docetaxel chemotherapy associated with PSA } \\
\text { response in CRPC patients }\end{array}$ & 97 & - & 94 \\
\hline \multirow[t]{2}{*}{ miR-223 } & Serum & $\begin{array}{l}\text { Prognostic, } \\
\text { diagnostic }\end{array}$ & Decrease in cancer vs normal. Increase in high risk vs low risk & 36 & 12 & 79 \\
\hline & Plasma & Diagnostic & Part of miRNA signature to distinguish $\mathrm{PCa}$ and $\mathrm{BPH}$ & 36 & 31 & 85 \\
\hline $\mathrm{miR}-30 \mathrm{Ib}$ & $\begin{array}{l}\text { Serum, } \\
\text { plasma }\end{array}$ & $\begin{array}{l}\text { Predictive, } \\
\text { prognostic }\end{array}$ & $\begin{array}{l}\text { High expression pre-docetaxel chemotherapy associated with PSA } \\
\text { response in CRPC patients }\end{array}$ & 97 & - & 94 \\
\hline \multirow[t]{4}{*}{ miR-375 } & Serum & Prognostic & Increase in patients with metastatic $\mathrm{PCa}$ & 113 & - & 87 \\
\hline & Serum & Prognostic & $\begin{array}{l}\text { Increase in serum EVs of metastatic PCa compared to } \\
\text { nonrecurrent PCa patients }\end{array}$ & 47 & 72 & 90 \\
\hline & Serum & Prognostic & $\begin{array}{l}\text { Increase in high-risk and CRPC serum samples compared to low- } \\
\text { risk ones. Increase in primary tumor vs normal tissue }\end{array}$ & 84 & - & 89 \\
\hline & Plasma & Prognostic & $\begin{array}{l}\text { Increased expression associated with shorter overall survival at } \\
4 \text { years after ADT failure and mortality at } 20 \text { months after ADT } \\
\text { failure }\end{array}$ & 100 & - & 91 \\
\hline miR-378* & Serum & Prognostic & $\begin{array}{l}\text { Increase in high-risk and CRPC serum samples compared to low- } \\
\text { risk localized ones. Decrease in low-risk localized and metastatic } \\
\text { tumor specimens vs normal tissue }\end{array}$ & 84 & - & 89 \\
\hline miR-429 & $\begin{array}{l}\text { Serum, } \\
\text { plasma }\end{array}$ & $\begin{array}{l}\text { Prognostic, } \\
\text { predictive }\end{array}$ & $\begin{array}{l}\text { Increase associated with decreased survival after docetaxel } \\
\text { chemotherapy in CRPC patients }\end{array}$ & 97 & - & 94 \\
\hline miR-433 & Serum & Prognostic & Increase in aggressive $\mathrm{PCa}$ & 12 & 4 & 80 \\
\hline miR-45I & Serum & $\begin{array}{l}\text { Diagnostic, } \\
\text { prognostic }\end{array}$ & $\begin{array}{l}\text { Increase in high risk vs healthy; no change between healthy, low-, } \\
\text { and intermediate-risk }\end{array}$ & 36 & 12 & 79 \\
\hline miR-56Ia-3p & Serum & Prognostic & Increase in patients with metastatic $\mathrm{PCa}$ & 113 & - & 87 \\
\hline miR-605 & Serum & Prognostic & Decrease in aggressive $\mathrm{PCa}$ & 12 & 4 & 80 \\
\hline miR-I246 & & Prognostic & $\begin{array}{l}\text { Increased expression correlated with pathological grade, positive } \\
\text { metastasis, poor prognosis, and tumor aggression in vitro and in } \\
\text { vivo }\end{array}$ & 6 & 6 & 113 \\
\hline miR-I 290 & Plasma & Prognostic & $\begin{array}{l}\text { Increased expression associated with shorter overall survival at } 4 \\
\text { years after ADT failure and mortality after ADT failure }\end{array}$ & 100 & - & 91 \\
\hline
\end{tabular}

Note: We apologize to the authors whose papers we were not able to include because of space limitations.

Abbreviations: ADT, androgen deprivation therapy; BPH, benign prostatic hyperplasia; CAPRA, Cancer of the Prostate Risk Assessment score; PCa, prostate cancer; RP, radical prostatectomy; CRPC, castration-resistant prostate cancer; mCRPC, metastatic CRPC; PSA, prostate-specific antigen; EVs, extracellular vesicles.

limited data are available. Lin et al found that high expression of miR-200a, miR-200b, and miR-429 before docetaxel chemotherapy treatment was associated with significantly worse overall survival in castration-resistant prostate cancer (CRPC) patients. ${ }^{94}$ Furthermore, these three miRNAs exhibited low expression in docetaxel-resistant compared to docetaxelsensitive PC3 and DU145 cell lines. The authors also noted that miR-200c, miR-200b, miR-146a, miR-222, miR-301b, and miR-20a expression before docetaxel treatment was associated with PSA response in CRPC patients. miR-21 was identified to be elevated in the serum of prostate cancer patients that later developed metastatic CRPC. ${ }^{95}$ It was also described as a predictive biomarker for docetaxel response, where patients with high pre-chemotherapy serum levels of miR-21 were found to be docetaxel resistant. ${ }^{95}$ With further research, perhaps these miRNAs will be able to identify a 
group of patients who should not receive docetaxel due to predicted resistance, but rather receive another systemic treatment. miR-375 and miR-1290 have been described as prognostic biomarkers, with their increased expression in plasma associated with shorter overall survival at 4 years after ADT failure and mortality at 20 months after ADT failure. ${ }^{91}$ More research is needed to establish whether these miRNAs actually have prognostic utility. Bertoli et al found that seven miRNAs previously described as prognostic biomarkers (ie, let-7a, miR-141, miR-145, miR-195, miR-221, miR-375, miR-451) showed poor prognostic accuracy using the TCGA data set as an independent validation data set. ${ }^{51}$ However, as TCGA has limited long-term outcomes data, these miRNAs may prove to be accurate prognostic biomarkers in the future. Validation of these predictive and prognostic miRNAs will yield an invaluable clinical tool for improved treatment planning and patient outcomes. From a clinical perspective, it is equally as important to be able to evaluate heterogeneity of a patient's disease as well as its future progression.

There are many articles on the discovery of tissue or urinary markers for prostate cancer risk stratification; ${ }^{12,13,48,49,96-100}$ however, those involving circulating miRNA biomarkers remain very limited. We have previously addressed the various uses and limitations of tissue markers. There are various advantages and disadvantages for using urinary miRNA biomarkers. As previously eluded to, a significant advantage to using urine as a biomarker source is the ability to collect urine from the prostate after a DRE, which will enrich the sample with prostate-specific miRNA. However, this can only be done in cases where patients have an intact prostate. Therefore, for patients who have undergone radical prostatectomy, urinary biomarkers are inferior to those from circulation. Furthermore, it is unclear whether circulating miRNAs are prevented from passing through the glomeruli and would be excluded from the urinary miRNome. If this is the case, urine samples would not contain miRNA from micro/metastatic cancer cells, and therefore, urinary biomarkers may not be representative of the systemic disease burden. Circulating miRNAs may be more representative of local and systemic disease compared to urine miRNA, particularly in such situations. In a proof of principle study, our group has demonstrated that circulating miRNAs are representative of prostate cancer risk stratification after radical prostatectomy. We found that high expression of the miR-17 family members (miR-17, miR-20a, miR-20b, and miR-106a) in serum could stratify patients into low- and high-risk groups, and their expression correlated with poor outcomes in the TCGA data set and an aggressive phenotype in vitro (Hoey et al, manuscript submitted). Future studies will confirm whether this circulating miRNA signature is prognostic and will correlate with disease progression and recurrence.

Identification and validation of diagnostic miRNA biomarkers is a more straightforward question, as seen in the number of papers on this topic. However, it is more difficult to identify clinically useful miRNA for the prognostic setting, ${ }^{88,91,95}$ and in particular, to tease apart the clinical heterogeneity of Gleason $3+4$ vs $4+3$ cancer (for which there are currently no published data). Furthermore, of the few studies investigating prognostic circulating miRNA biomarkers, the outcomes used are for radical prostatectomy and not radiotherapy. There is a need for large-scale studies on circulating miRNAs looking at long-term clinical outcomes (in both surgical and radiotherapy settings) in order to determine which miRNA will prove to be clinically useful for prostate cancer risk stratification. As it currently stands, we are limited by experimental design, undeveloped outcomes data, and small sample sizes.

\section{Methods for detecting and measuring circulating blood miRNAs}

For a biomarker to be feasibly implemented in the clinic, its measurement must be assayed by cost-effective and reproducible means. Currently, the most commonly used techniques for measuring the expression of circulating blood miRNAs are quantitative reverse transcription (qRT)-PCR, NanoString, and next-generation sequencing (NGS). ${ }^{50,101,102}$ These platforms have been compared for miRNA profiling in patient samples. In a study by Blondal et al, both qRT-PCR and NGS showed high reproducibility between replicates (Pearson $\left.R^{2}=0.9494\right) .{ }^{101}$ Similarly, a study by Knutsen et al found high correlation between replicates of the same platform: miRCURY RT-quantitative PCR (qPCR), $R=0.997 \pm 0.010$; NanoString nCounter, $R=0.992 \pm 0.008$; and Sequencing by Oligonucleotide Ligation and Detection (SOLiD) NGS, $R=0.924 \pm 0.026 .{ }^{103}$ It was found that, between Illumina NGS and miRCURY RT-qPCR platforms, there was a moderate agreement between miRNA expression levels $\left(R^{2}=0.6054\right) .{ }^{101}$ In a different study, two NGS platforms (SOLiD4 and Illumina HiSeq) showed high concordance between miRNA expressions. ${ }^{103}$ Although the relative trend for miRNA expression (ie, whether it is upregulated or downregulated) has been found to be consistent, there is poor correlation between $P$-values from different platforms, which can cause large ambiguity in results. ${ }^{101}$ Furthermore, they found that highly expressed miRNAs (average $>100$ 
tags per million [TPM] mapped reads) showed the strongest correlation between platforms $\left(R^{2}=0.812\right)$. NGS was found to be particularly useful at identifying isomiRs and novel miRNA, which qPCR cannot do. NGS was unable to accurately distinguish miRNA expression with small-fold changes and low TPM ranges. ${ }^{101}$ Similarly, NanoString is also known to have low sensitivity, especially in low-input RNA samples like serum and plasma. ${ }^{104}$ Another study showed high sensitivity for miRNA profiling with SOLiD4 NGS (0.982), Illumina HiSeq NGS (0.983), and miRCURY qPCR (0.959), whereas NanoString nCounter showed the lowest sensitivity (0.645). ${ }^{103}$ NanoString and qPCR platforms are believed to have lower sensitivity due to a limited number of primers and probes, whereas NGS is able to detect novel miRNA that had not previously been discovered. Overall, these authors recommended a combination of platforms to be used.

\section{Plasma vs serum miRNA}

miRNA from the blood can be collected in plasma or serum fractions and both are described in the literature. Plasma is the cell-free supernatant yielded after centrifugation of blood that is collected in the presence of anticoagulants. Serum, on the other hand, is the cell-free supernatant yielded after centrifugation of blood collected in the absence of anticoagulants. miRNA found in both plasma and serum can be satisfactorily collected for downstream applications; however, there are factors that distinguish the two based on the presence/absence of anticoagulants. Since plasma is blood with anticoagulants, minimal blood cell lysis occurs, yielding plasma miRNAs from tissue rather than blood cells. As blood cells contain significant amounts of RNA, serum miRNA from the tumor may be diluted with that from blood cells, and therefore plasma miRNA may contain a higher proportion of tumor miRNA. ${ }^{105}$ Serum, as previously eluded to, would likely contain more miRNA originating from blood cells, as the coagulation process may cause stress on blood cells and stimulate the release of RNA. ${ }^{105}$ However, blood cell-specific miRNAs have been found in both serum and plasma components at a similar level. ${ }^{105}$ Serum appears to be the current biofluid of choice, as most articles in the literature on bloodbased miRNA biomarkers use serum fractions. This may be because plasma miRNA collection and measurement have more confounding variables than that of serum. A significant confounding variable is that contamination of cells from the cellular pellet often occurs during aspiration, making plasma miRNA collection more technically challenging than that from serum. ${ }^{106}$ Anticoagulants used in plasma collection are known to affect downstream qRT-PCR applications. EDTA, heparin, and citrate anticoagulants have been described as acceptable for downstream PCR by some sources; however, other sources have found the opposite. ${ }^{106-108}$ Furthermore, there is no standardized anticoagulant used among laboratories; so plasma miRNA trends identified from different laboratories may be highly variable. However, it has been shown that plasma and serum miRNAs are strongly correlated, ${ }^{52}$ so both methods are likely acceptable sources for circulating miRNA biomarkers.

\section{Challenges and future directions}

Despite the promise of circulating miRNAs as biomarkers, there are various challenges that must be addressed before their implementation in the clinic. There is currently no standardized method for miRNA detection in biofluids. There is large variability between the results of miRNA detection and measurement between platforms and even between laboratories using the same platform but from a different company. ${ }^{50}$ For example, it was shown that miRNA expression has a low correlation between Affymetrix and Agilent systems. ${ }^{50}$ This also makes the validation of results especially difficult, and validation is imperative before use in the clinic. Another challenge is being able to distinguish miRNA paralogs, which have a high degree of sequence conservation. ${ }^{101}$ Furthermore, it is also difficult to distinguish between precursor and mature miRNA forms. Another limitation is that there is currently no good normalization control. Since miRNA expressions show large variability between healthy and disease states, and between individuals - giving it a strong biomarker potential - it also means that miRNAs that are sometimes used as controls will not even be detectable in other settings. One way to combat this issue is to use "spike-ins," where a known concentration of a certain miRNA is added to the sample before any processing. ${ }^{101,104}$ Detected miRNA concentrations are calculated relative to the spike-in levels. Liquid biopsies also hold another limitation where they cannot distinguish miRNA originating from the tumor tissue of interest compared to that from another tissue.

Although many miRNAs have been described as biomarkers, to our knowledge, no large prospective study has validated miRNA biomarkers for diagnosis, therapy response prediction, or prognostication. More large cohort studies are needed to generate a consensus on circulating miRNAs for risk stratification in prostate cancer. Furthermore, another issue of prognostic biomarker discovery is the need to wait at least 5 years - or 10-15 years - for clinically relevant prospective outcomes data. With the first miRNA having 


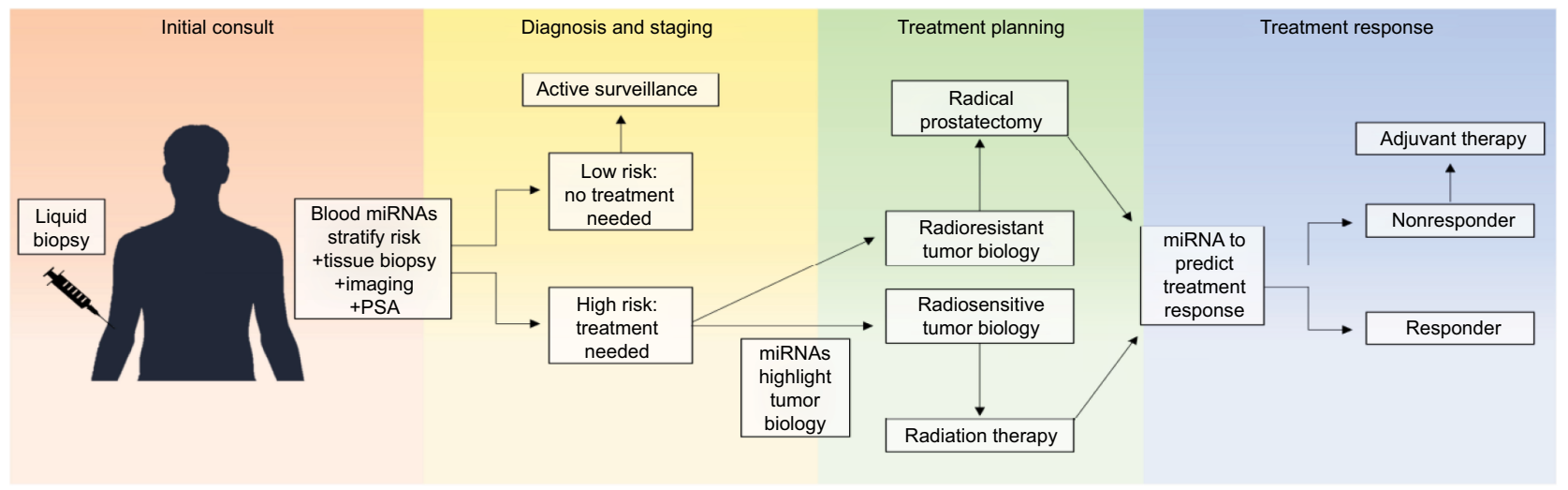

Figure I The future of prostate cancer risk stratification.

Notes: Validated circulating blood miRNAs could prove to be a useful tool for prostate cancer risk stratification - independently or in addition to current staging tools, such as PSA, histological grade, and imaging. More accurate risk stratification will allow for appropriate treatment management, leading to better tumor control, reduced side effects due to overtreatment, and ultimately, improved patient outcomes.

Abbreviation: PSA, prostate-specific antigen.

been discovered in $1993^{109}$ and the second only in $2000,{ }^{110-112}$ there are few studies with data that are mature enough for sufficient prognostic utility. Future studies must address these issues before a robust circulating miRNA biomarker test can be generated and used in the patient setting.

\section{Conclusion}

Circulating miRNAs have promising biomarker utility. With diagnostic miRNAs that can distinguish cancer from BPH, we will be less reliant on biopsies; with predictive miRNAs that can suggest which tumors may or may not respond to certain treatments, patients will receive the best treatment for their disease upfront; and with prognostic miRNAs that can identify which tumors will be more aggressive, we may find that treatment escalation or systemic therapies will improve patient outcomes. We are beginning to unravel the utility of circulating miRNAs, although we have a long way to go. Their future incorporation into clinical practice will not only improve the specificity of PSA and MRI biomarkers, but will also help limit or avoid the need for initial or subsequent invasive biopsies. These circulating biomarkers have the potential to expand the scope of personalized medicine.

The forefront of prostate cancer risk stratification is moving toward the use of circulating biomarkers. Circulating miRNAs are especially promising biomarkers due to their extensive preclinical characterization of miRNAs, their representation of the underlying tumor landscape, and inherent properties making for a smooth transition into clinical practice. Once these miRNAs are validated in large prospective cohorts, they can be used in addition to histopathology, imaging, and PSA to more accurately stratify patients (Figure 1). The goal is that, in the future, miRNA biomarkers will be used to establish prostate cancer patient risk status and eliminate the need for biopsies altogether. More accurate risk stratification will lead to improved tumor control from appropriate treatment management and reduced side effects due to overtreatment, to ultimately improve patient outcomes.

\section{Acknowledgements}

The authors would like to thank the generous support provided by Prostate Cancer Canada, Movember Foundation (Movember Rising Star award recipient, Grants \# RS201403, \#D2013-24), Telus Motorcycle Ride For Dad (Huronia Branch), and a Ministry of Research and Innovation Early Researcher Award. CH was supported by the Strategic Training in Transdisciplinary Radiation Science for the 21st Century (STARS21) training program funded by the Terry Fox Foundation; Princess Margaret Cancer Centre; the Government of Ontario; and Lawrence, Ila, and William Gifford Scholarship in Radiation Oncology and Surgery at the University of Toronto. CH was also a recipient of the Queen Elizabeth II Graduate Scholarship in Science and Technology (QEII-GSST) funded by Sunnybrook Health Sciences Centre, University of Toronto, and the Government of Ontario.

\section{Disclosure}

The authors report no conflicts of interest in this work.

\section{References}

1. Wong MC, Goggins WB, Wang HH, et al. Global incidence and mortality for prostate cancer: analysis of temporal patterns and trends in 36 countries. Eur Urol. 2016;70(5):862-874. 
2. D'Amico AV, Whittington R, Malkowicz SB, et al. Biochemical outcome after radical prostatectomy, external beam radiation therapy, or interstitial radiation therapy for clinically localized prostate cancer. JAMA. 1998;280(11):969-974.

3. Cooperberg MR, Pasta DJ, Elkin EP, et al. The University of California, San Francisco cancer of the prostate risk assessment score: a straightforward and reliable preoperative predictor of disease recurrence after radical prostatectomy. J Urol. 2005;173(6):1938-1942.

4. Humphrey PA. Gleason grading and prognostic factors in carcinoma of the prostate. Mod Pathol. 2004;17(3):292-306.

5. Loeb S, Vellekoop A, Ahmed HU, et al. Systematic review of complications of prostate biopsy. Eur Urol. 2013;64(6):876-892.

6. Rudzinski JK, Kawakami J. Incidence of infectious complications following transrectal ultrasound-guided prostate biopsy in Calgary, Alberta, Canada: a retrospective population-based analysis. Can Urol Assoc J. 2014;8(5-6):301-305.

7. Müntener M, Epstein JI, Hernandez DJ, et al. Prognostic significance of Gleason score discrepancies between needle biopsy and radical prostatectomy. Eur Urol. 2008;53(4):767-776.

8. Pokorny MR, de Rooij M, Duncan E, et al. Prospective study of diagnostic accuracy comparing prostate cancer detection by transrectal ultrasound-guided biopsy versus magnetic resonance (MR) imaging with subsequent MR-guided biopsy in men without previous prostate biopsies. Eur Urol. 2014;66(1):22-29.

9. Ahmed HU, El-Shater Bosaily A, Brown LC, et al. Diagnostic accuracy of multi-parametric MRI and TRUS biopsy in prostate cancer (PROMIS): a paired validating confirmatory study. Lancet. 2017;389(10071):815-822.

10. Kasivisvanathan V, Rannikko AS, Borghi M, et al. MRI-Targeted or standard biopsy for prostate-cancer diagnosis. $N$ Engl J Med. 2018;378(19):1767-1777.

11. Johnson DC, Raman SS, Mirak SA, et al. Detection of individual prostate cancer foci via multiparametric magnetic resonance imaging. Eur Urol. 2018.

12. Erho N, Crisan A, Vergara IA, et al. Discovery and validation of a prostate cancer genomic classifier that predicts early metastasis following radical prostatectomy. PLoS One. 2013;8(6):e66855.

13. Gore JL, du Plessis M, Santiago-Jiménez M, et al. Decipher test impacts decision making among patients considering adjuvant and salvage treatment after radical prostatectomy: interim results from the multicenter prospective PRO-IMPACT study. Cancer. 2017;123(15):2850-2859.

14. Cuzick J, Swanson GP, Fisher G, et al. Prognostic value of an RNA expression signature derived from cell cycle proliferation genes in patients with prostate cancer: a retrospective study. Lancet Oncol. 2011;12(3):245-255.

15. Lalonde E, Alkallas R, Chua MLK, et al. Translating a prognostic DNA genomic classifier into the clinic: retrospective validation in 563 localized prostate tumors. Eur Urol. 2017;72(1):22-31.

16. Larrea E, Sole C, Manterola L, et al. New concepts in cancer biomarkers: circulating miRNAs in liquid biopsies. Int $\mathrm{J} \mathrm{Mol} \mathrm{Sci}$. 2016;17(5):627.

17. Hessels D, Klein Gunnewiek JM, van Oort I, et al. DD3(PCA3)-based molecular urine analysis for the diagnosis of prostate cancer. Eur Urol. 2003;44(1):8-16.

18. Roobol MJ, Schröder FH, van Leeuwen P, et al. Performance of the prostate cancer antigen 3 (PCA3) gene and prostate-specific antigen in prescreened men: exploring the value of PCA3 for a first-line diagnostic test. Eur Urol. 2010;58(4):475-481.

19. Vickers AJ, Cronin AM, Aus G, et al. A panel of kallikrein markers can reduce unnecessary biopsy for prostate cancer: data from the European randomized study of prostate cancer screening in Göteborg, Sweden. BMC Med. 2008;6(1):19.

20. Sjoberg DD, Vickers AJ, Assel M, et al. Twenty-year risk of prostate cancer death by midlife prostate-specific antigen and a panel of four kallikrein markers in a large population-based cohort of healthy men. Eur Urol. 2018;73(6):941-948.
21. Vickers A, Cronin A, Roobol M, et al. Reducing unnecessary biopsy during prostate cancer screening using a four-kallikrein panel: an independent replication. J Clin Oncol. 2010;28(15):2493-2498.

22. Bryant RJ, Sjoberg DD, Vickers AJ, et al. Predicting high-grade cancer at ten-core prostate biopsy using four kallikrein markers measured in blood in the ProtecT study. J Natl Cancer Inst. 2015;107(7).

23. Vickers AJ, Aus G. Impact of recent screening on predicting the outcome of prostate cancer biopsy in men with elevated prostatespecific antigen: data from the European randomized study of prostate cancer screening in Gothenburg, Sweden. Cancer. 2010;116(11): 2612-2620.

24. Benchikh A, Savage C, Cronin A, et al. A panel of kallikrein markers can predict outcome of prostate biopsy following clinical workup: an independent validation study from the European randomized study of prostate cancer screening, France. BMC Cancer. 2010;10(1):635.

25. Gupta A, Roobol MJ, Savage CJ, et al. A four-kallikrein panel for the prediction of repeat prostate biopsy: data from the European randomized study of prostate cancer screening in Rotterdam, Netherlands. $\mathrm{Br}$ J Cancer. 2010;103(5):708-714.

26. Parekh DJ, Punnen S, Sjoberg DD, et al. A multi-institutional prospective trial in the USA confirms that the 4 Kscore accurately identifies men with high-grade prostate cancer. Eur Urol. 2015;68(3):464-470.

27. Konety B, Zappala SM, Parekh DJ, et al. The 4 Kscore ${ }^{\circledR}$ test reduces prostate biopsy rates in community and academic urology practices. Rev Urol. 2015;17(4):231-240.

28. Sita-Lumsden A, Dart DA, Waxman J, Bevan CL. Circulating microRNAs as potential new biomarkers for prostate cancer. $\mathrm{Br} J$ Cancer. 2013;108(10):1925-1930.

29. Kuner R, Brase JC, Sültmann H, Wuttig D. microRNA biomarkers in body fluids of prostate cancer patients. Methods. 2013;59(1):132-137.

30. Sempere LF. Integrating contextual miRNA and protein signatures for diagnostic and treatment decisions in cancer. Expert Rev Mol Diagn. 2011;11(8):813-827.

31. He L, Hannon GJ. MicroRNAs: small RNAs with a big role in gene regulation. Nat Rev Genet. 2004;5(7):522-531.

32. Friedländer MR, Lizano E, Houben AJ, et al. Evidence for the biogenesis of more than 1,000 novel human microRNAs. Genome Biol. 2014;15(4):R57.

33. Lewis BP, Burge CB, Bartel DP. Conserved seed pairing, often flanked by adenosines, indicates that thousands of human genes are microRNA targets. Cell. 2005;120(1):15-20.

34. Chekulaeva M, Filipowicz W. Mechanisms of miRNA-mediated post-transcriptional regulation in animal cells. Curr Opin Cell Biol. 2009;21(3):452-460.

35. Huntzinger E, Izaurralde E. Gene silencing by microRNAs: contributions of translational repression and mRNA decay. Nat Rev Genet. 2011;12(2):99-110.

36. Ben-Hamo R, Efroni S. MicroRNA regulation of molecular pathways as a generic mechanism and as a core disease phenotype. Oncotarget. 2015;6(3):1594-1604

37. Vanacore D, Boccellino M, Rossetti S, et al. MicroRNAs in prostate cancer: an overview. Oncotarget. 2017;8(30):50240-50251.

38. Luu HN, Lin HY, Sørensen KD, et al. miRNAs associated with prostate cancer risk and progression. BMC Urol. 2017;17(1):18.

39. Huang X, Taeb S, Jahangiri S, et al. miRNA-95 mediates radioresistance in tumors by targeting the sphingolipid phosphatase SGPP1. Cancer Res. 2013;73(23):6972-6986.

40. Hoey C, Ray J, Jeon J, et al. miRNA-106a and prostate cancer radioresistance: a novel role for LITAF in ATM regulation. Mol Oncol. 2018;12(8):1324-1341.

41. Mesci A, Huang X, Taeb S, et al. Targeting of CCBE1 by miR330-3p in human breast cancer promotes metastasis. Br J Cancer. 2017;116(10):1350-1357.

42. Huang $X$, Taeb S, Jahangiri S, et al. miR-620 promotes tumor radioresistance by targeting 15-hydroxyprostaglandin dehydrogenase (HPGD). Oncotarget. 2015;6(26):22439-22451. 
43. Valadi H, Ekström K, Bossios A, Sjöstrand M, Lee JJ, Lötvall JO. Exosome-mediated transfer of mRNAs and microRNAs is a novel mechanism of genetic exchange between cells. Nat Cell Biol. 2007;9(6):654-659.

44. Théry C, Zitvogel L, Amigorena S. Exosomes: composition, biogenesis and function. Nat Rev Immunol. 2002;2(8):569-579.

45. Simons M, Raposo G. Exosomes--vesicular carriers for intercellular communication. Curr Opin Cell Biol. 2009;21(4):575-581.

46. Melo SA, Sugimoto H, O'Connell JT, et al. Cancer exosomes perform cell-independent microRNA biogenesis and promote tumorigenesis. Cancer Cell. 2014;26(5):707-721.

47. Pellegrini KL, Patil D, Douglas KJS, et al. Detection of prostate cancerspecific transcripts in extracellular vesicles isolated from post-DRE urine. Prostate. 2017;77(9):990-999.

48. Mckiernan J, Donovan MJ, O'Neill V, et al. A novel urine exosome gene expression assay to predict high-grade prostate cancer at initial biopsy. JAMA Oncol. 2016;2(7):882-889.

49. Donovan MJ, Torkler P, Noerholm M, Skog J, Mckiernan JM. Performance of a clinically validated urine exosome gene expression test to predict high grade prostate cancer in men with a prior negative biopsy. J Clin Oncol. 2018;36(6_suppl):119.

50. Etheridge A, Lee I, Hood L, Galas D, Wang K. Extracellular microRNA: a new source of biomarkers. Mutat Res. 2011;717(1-2):85-90.

51. Bertoli G, Cava C, Castiglioni I. MicroRNAs as biomarkers for diagnosis, prognosis and theranostics in prostate cancer. Int J Mol Sci. 2016;17(3):421.

52. Mitchell PS, Parkin RK, Kroh EM, et al. Circulating microRNAs as stable blood-based markers for cancer detection. Proc Natl Acad Sci U S A. 2008;105(30):10513-10518.

53. Presti JC. Prostate biopsy: current status and limitations. Rev Urol. 2007;9(3):93-98.

54. Werahera PN, Crawford ED, La Rosa FG, et al. Anterior tumors of the prostate: diagnosis and significance. Can JUrol.2013;20(5):6897-6906.

55. Evans SM, Patabendi Bandarage V, Kronborg C, Earnest A, Millar J, Clouston D. Gleason group concordance between biopsy and radical prostatectomy specimens: a cohort study from prostate cancer outcome registry - Victoria. Prostate Int. 2016;4(4):145-151.

56. Kvåle R, Møller B, Wahlqvist R, et al. Concordance between Gleason scores of needle biopsies and radical prostatectomy specimens: a population-based study. BJU Int. 2009;103(12):1647-1654.

57. King CR. Patterns of prostate cancer biopsy grading: trends and clinical implications. Int J Cancer. 2000;90(6):305-311.

58. Epstein JI, Feng Z, Trock BJ, Pierorazio PM. Upgrading and downgrading of prostate cancer from biopsy to radical prostatectomy: incidence and predictive factors using the modified Gleason grading system and factoring in tertiary grades. Eur Urol. 2012;61(5):1019-1024.

59. Burchardt M, Engers R, Müller M, et al. Interobserver reproducibility of Gleason grading: evaluation using prostate cancer tissue microarrays. J Cancer Res Clin Oncol. 2008;134(10):1071-1078.

60. Townsend NC, Ruth K, Al-Saleem T, et al. Gleason scoring at a comprehensive cancer center: what's the difference? J Natl Compr Canc Netw. 2013;11(7):812-819.

61. Allsbrook WC, Mangold KA, Johnson MH, et al. Interobserver reproducibility of Gleason grading of prostatic carcinoma: urologic pathologists. Hum Pathol. 2001;32(1):74-80.

62. di Loreto C, Fitzpatrick B, Underhill S, et al. Correlation between visual clues, objective architectural features, and interobserver agreement in prostate cancer. Am J Clin Pathol. 1991;96(1):70-75.

63. Gupta RT, Kauffman CR, Polascik TJ, Taneja SS, Rosenkrantz AB. The state of prostate MRI in 2013. Oncology. 2013;27(4): 262-270.

64. Hocking J, Mithraprabhu S, Kalff A, Spencer A. Liquid biopsies for liquid tumors: emerging potential of circulating free nucleic acid evaluation for the management of hematologic malignancies. Cancer Biol Med. 2016;13(2):215-225.

65. Krishnamurthy N, Spencer E, Torkamani A, Nicholson L. Liquid biopsies for cancer: coming to a patient near you. J Clin Med. 2017;6(1):3.
66. Dall'era MA, Klotz L. Active surveillance for intermediate-risk prostate cancer. Prostate Cancer Prostatic Dis. 2017;20(1):1-6.

67. Morash C, Tey R, Agbassi C, et al. Active surveillance for the management of localized prostate cancer: guideline recommendations. Can Urol Assoc J. 2015;9(5-6):171-178.

68. Klotz L, Vesprini D, Sethukavalan P, et al. Long-term follow-up of a large active surveillance cohort of patients with prostate cancer. J Clin Oncol. 2015;33(3):272-277.

69. Mohler J, Bahnson RR, Boston B, et al. NCCN clinical practice guidelines in oncology: prostate cancer. J Natl Compr Canc Netw. 2010;8(2):162-200.

70. Stark JR, Perner S, Stampfer MJ, et al. Gleason score and lethal prostate cancer: does 3 + 4= 4 + 3? J Clin Oncol. 2009;27(21):3459-3464.

71. Viers BR, Sukov WR, Gettman MT, et al. Primary Gleason grade 4 at the positive margin is associated with metastasis and death among patients with Gleason 7 prostate cancer undergoing radical prostatectomy. Eur Urol. 2014;66(6):1116-1124.

72. Wright JL, Salinas CA, Lin DW, et al. Prostate cancer specific mortality and Gleason 7 disease differences in prostate cancer outcomes between cases with Gleason $4+3$ and Gleason $3+4$ tumors in a population based cohort. J Urol. 2009;182(6):2702-2707.

73. Epstein JI, Zelefsky MJ, Sjoberg DD, et al. A contemporary prostate cancer grading system: a validated alternative to the Gleason score Eur Urol. 2016;69(3):428-435.

74. Brimo F, Montironi R, Egevad L, et al. Contemporary grading for prostate cancer: implications for patient care. Eur Urol. 2013;63(5):892-901

75. Epstein JI. Prostate cancer grading: a decade after the 2005 modified system. Mod Pathol. 2018;31(S1):S47-63.

76. Musunuru HB, Yamamoto T, Klotz L, et al. Active surveillance for intermediate risk prostate cancer: survival outcomes in the Sunnybrook experience. J Urol. 2016;196(6):1651-1658.

77. Keane FK, Chen MH, Zhang D, et al. The likelihood of death from prostate cancer in men with favorable or unfavorable intermediate-risk disease. Cancer. 2014;120(12):1787-1793.

78. Lodes MJ, Caraballo M, Suciu D, Munro S, Kumar A, Anderson B. Detection of cancer with serum miRNAs on an oligonucleotide microarray. PLoS One. 2009;4(7):e6229.

79. Moltzahn F, Olshen AB, Baehner L, et al. Microfluidic-based multiplex qRT-PCR identifies diagnostic and prognostic microRNA signatures in the sera of prostate cancer patients. Cancer Res. 2011;71(2): $550-560$.

80. Alhasan AH, Scott AW, Wu JJ, et al. Circulating microRNA signature for the diagnosis of very high-risk prostate cancer. Proc Natl Acad Sci USA. 2016;113(38):10655-10660.

81. Mahn R, Heukamp LC, Rogenhofer S, von Ruecker A, Müller SC, Ellinger J. Circulating microRNAs (miRNA) in serum of patients with prostate cancer. Urology. 2011;77(5):1265.e9-121265.

82. Li Z, Ma YY, Wang J, et al. Exosomal microRNA-141 is upregulated in the serum of prostate cancer patients. Onco Targets Ther. 2016;9: $139-148$

83. Kelly BD, Miller N, Sweeney KJ, et al. A circulating microRNA signature as a biomarker for prostate cancer in a high risk group. $J$ Clin Med. 2015;4(7):1369-1379.

84. Liu RSC, Olkhov-Mitsel E, Jeyapala R, et al. Assessment of serum microRNA biomarkers to predict reclassification of prostate cancer in patients on active surveillance. $J$ Urol. 2018;199(6): 1475-1481.

85. Sharova E, Grassi A, Marcer A, et al. A circulating miRNA assay as a first-line test for prostate cancer screening. Br J Cancer. 2016;114(12):1362-1366.

86. Shen J, Hruby GW, Mckiernan JM, et al. Dysregulation of circulating microRNAs and prediction of aggressive prostate cancer. Prostate. 2012;72(13):1469-1477.

87. Brase JC, Johannes M, Schlomm T, et al. Circulating miRNAs are correlated with tumor progression in prostate cancer. Int $J$ Cancer. 2011;128(3):608-616. 
88. Zhang HL, Qin XJ, Cao DL, et al. An elevated serum miR-141 level in patients with bone-metastatic prostate cancer is correlated with more bone lesions. Asian J Androl. 2013;15(2):231-235.

89. Nguyen HC, Xie W, Yang M, et al. Expression differences of circulating microRNAs in metastatic castration resistant prostate cancer and low-risk, localized prostate cancer. Prostate. 2013;73(4): 346-354.

90. Bryant RJ, Pawlowski T, Catto JWF, et al. Changes in circulating microRNA levels associated with prostate cancer. Br J Cancer. 2012;106(4):768-774.

91. Huang X, Yuan T, Liang M, et al. Exosomal miR-1290 and miR-375 as prognostic markers in castration-resistant prostate cancer. Eur Urol. 2015;67(1):33-41.

92. Al-Qatati A, Akrong C, Stevic I, et al. Plasma microRNA signature is associated with risk stratification in prostate cancer patients. Int $J$ Cancer. 2017;141(6):1231-1239.

93. Oldenhuis CN, Oosting SF, Gietema JA, de Vries EG. Prognostic versus predictive value of biomarkers in oncology. Eur J Cancer. 2008;44(7):946-953.

94. Lin HM, Castillo L, Mahon KL, et al. Circulating microRNAs are associated with docetaxel chemotherapy outcome in castration-resistant prostate cancer. Br J Cancer. 2014;110(10):2462-2471.

95. Zhang HL, Yang LF, Zhu Y, et al. Serum miRNA-21: elevated levels in patients with metastatic hormone-refractory prostate cancer and potential predictive factor for the efficacy of docetaxel-based chemotherapy. Prostate. 2011;71(3):326-331.

96. Nam RK, Amemiya Y, Benatar T, et al. Identification and validation of a five microRNA signature predictive of prostate cancer recurrence and metastasis: a cohort study. J Cancer. 2015;6(11):1160-1171.

97. Long Q, Johnson BA, Osunkoya AO, et al. Protein-coding and microRNA biomarkers of recurrence of prostate cancer following radical prostatectomy. Am J Pathol. 2011;179(1):46-54.

98. Fendler A, Jung M, Stephan C, et al. miRNAs can predict prostate cancer biochemical relapse and are involved in tumor progression. Int J Oncol. 2011;39(5):1183-1192.

99. Zhao Z, Stephan C, Weickmann S, Jung M, Kristiansen G, Jung K. Tissue-based microRNAs as predictors of biochemical recurrence after radical prostatectomy: what can we learn from past studies? Int J Mol Sci. 2017;18(10):2023.

100. Bell EH, Kirste S, Fleming JL, et al. A novel miRNA-based predictive model for biochemical failure following post-prostatectomy salvage radiation therapy. PLoS One. 2015;10(3):e0118745.
101. Blondal T, Brunetto MR, Cavallone D, et al. Genome-wide comparison of next-generation sequencing and qPCR platforms for microRNA profiling in serum. Methods Mol Biol. 2017;1580:21-44.

102. Foye C, Yan IK, David W, et al. Comparison of miRNA quantitation by Nanostring in serum and plasma samples. PLoS One. 2017;12(12): e0189165.

103. Knutsen E, Fiskaa T, Ursvik A, et al. Performance comparison of digital microRNA profiling technologies applied on human breast cancer cell lines. PLoS One. 2013;8(10):e75813.

104. Tay JW, James I, Hughes QW, Tiao JY, Baker RI. Identification of reference miRNAs in plasma useful for the study of oestrogen-responsive miRNAs associated with acquired protein $\mathrm{S}$ deficiency in pregnancy. BMC Res Notes. 2017;10(1):312.

105. Wang K, Yuan Y, Cho JH, Mcclarty S, Baxter D, Galas DJ. Comparing the microRNA spectrum between serum and plasma. PLoS One. 2012;7(7):e41561.

106. Kroh EM, Parkin RK, Mitchell PS, Tewari M. Analysis of circulating microRNA biomarkers in plasma and serum using quantitative reverse transcription-PCR (qRT-PCR). Methods. 2010;50(4):298-301.

107. García ME, Blanco JL, Caballero J, Gargallo-Viola D. Anticoagulants interfere with PCR used to diagnose invasive aspergillosis. J Clin Microbiol. 2002;40(4):1567-1568.

108. Friedland LR, Menon AG, Reising SF, Ruddy RM, Hassett DJ. Development of a polymerase chain reaction assay to detect the presence of Streptococcus pneumoniae DNA. Diagn Microbiol Infect Dis. 1994;20(4):187-193.

109. Lee RC, Feinbaum RL, Ambros V. The C. elegans heterochronic gene lin-4 encodes small RNAs with antisense complementarity to lin-14. Cell. 1993;75(5):843-854.

110. Reinhart BJ, Slack FJ, Basson M, et al. The 21-nucleotide let-7 RNA regulates developmental timing in Caenorhabditis elegans. Nature. 2000;403(6772):901-906.

111. Pasquinelli AE, Reinhart BJ, Slack F, et al. Conservation of the sequence and temporal expression of let-7 heterochronic regulatory RNA. Nature. 2000;408(6808):86-89.

112. Slack FJ, Basson M, Liu Z, Ambros V, Horvitz HR, Ruvkun G. The LIN$41 \mathrm{RBCC}$ gene acts in the $\mathrm{C}$. elegans heterochronic pathway between the let-7 regulatory RNA and the LIN-29 transcription factor. Mol Cell. 2000;5(4):659-669.

113. Bhagirath D, Yang TL, Bucay N, et al. microRNA-1246 is an exosomal biomarker for aggressive prostate cancer. Cancer Res. 2018;78(7):1833-1844.
Research and Reports in Urology

\section{Publish your work in this journal}

Research and Reports in Urology is an international, peer-reviewed, open access journal publishing original research, reports, editorials, reviews and commentaries on all aspects of adult and pediatric urology in the clinic and laboratory including the following topics: Pathology, pathophysiology of urological disease; Investigation and treatment of

\section{Dovepress}

urological disease; Pharmacology of drugs used for the treatment of urological disease. The manuscript management system is completely online and includes a very quick and fair peer-review system, which is all easy to use. Visit http://www.dovepress.com/testimonials.php to read real quotes from published authors. 